\title{
Effects of Worked Example on Experts' Procedural Skills in Solving Geometry Problems
}

\author{
Baiq W. Widyastuti ${ }^{1, *}$ Endah Retnowati ${ }^{2}$ \\ ${ }^{1}$ Graduate School of Mathematics Education, Universitas Negeri Yogyakarta, Yogyakarta, Indonesia \\ ${ }^{2}$ Department of Mathematics, Faculty of Mathematics and Natural Science, Universitas Negeri Yogyakarta, \\ Yogyakarta, Indonesia \\ *Corresponding author. Email: baiq.weny2015@student.uny.ac.id
}

\begin{abstract}
Cognitive load theory is an instructional theory that concern to designing an effective learning strategy based on human cognitive system. Worked example was designed based on this theory. Through worked example, students are presented with examples and similar problem solving tasks. This method is believe to reduce extraneous cognitive load. Recent studies reveals that worked example are highly effective for novices, then further tests are needed on effects of this strategy for experts. To test these, total of 118 junior high school students are asked to solve geometry problems and they measured on procedural skills. This experiment compared two levels of learner prior knowledge (expert vs novice) and two learning strategies (worked example vs problem solving). It can be concluded that prior knowledge plays an important role in the effectiveness of learning strategy. Worked example enhanced procedural skills of novices, but it does not effect on experts. Minimum guidance such as problem solving strategy was more effective for experts. Giving worked example to experts causes redundancy effect and extraneous cognitive load. These findings for educational practice in mathematics suggest teacher to designing effective learning strategy by considered students' prior knowledge.
\end{abstract}

Keywords: Worked example, experts, procedural skills, mathematics.

\section{INTRODUCTION}

Polya described problem solving as a characteristic of human activity. The main goal of learning mathematics is to make students able to solve problems well. Two reasons the importance of mastering problem solving; first, problem solving is an ongoing process, it means problem solving start when students recognized the problems and ends with solutions; second, problem solving is a gradual process that aims to understand the problems and solved it using almost the same strategy even though the problem looks different. Problem solving allows students to determine steps and strategies depending on their prior knowledge. Prior knowledge and their experience of solving problems previously required students when facing new problems. Prior knowledge will help students to understand the problems and determine their actions and choose the right strategies [1]

Process of learning involves memory system to processing the information. The information will be processed by memory system so that it can be recognized, organized and responded. According to cognitive load theory, working memory plays an important role in learning. The function of working memory is to collect information, give meaning to information, and construct knowledge to be stored in long-term memory [2]. Besides, working memory has a limited capacity and duration. Working memory load occurs if too many information elements are processed by students during learning. If this happens simultaneously it will reduce the capacity and performance of working memory which can interfere learning [3]. Then teacher must control the amount of information that presented for students to avoid extraneous cognitive.

Based on perspective of cognitive load theory, learning is an activity to activate germane cognitive load and reduce extraneous cognitive load [4]. One of strategies to minimize extraneous cognitive load by providing worked example strategy. This strategy asked students to learn from example given. Worked examples are problem solving strategies that are accompanied with explicit guidance of each steps [5]. This guidance aims to 
help and provides prior knowledge for students. Through these examples, students are facilitated to construct their knowledge by following the example.

However, recent study showed that worked examples are effective to facilitating novice students. It is necessary to know how this strategy impacts for experts. As teachers, the needs of experts and novices must be equally considered. The difference in knowledge base between novices and experts requires different ways to facilitate their learning. This experiment involved worked example strategy and problem solving strategy to examine the right strategy for students according to their knowledge base. Therefore, this study is very important because it requires an empirical data about the impact of giving worked example for experts, and also to find out the right strategies for experts.

\subsection{Procedural Skills}

Procedural skill is defined as the ability to carry out appropriate procedures and to be able to use several ways to solve problems [6]. Kilpatrick revealed that procedural skills requires an understanding of several concepts and examples to enable students to use the procedure with different methods, and most important students know when the procedure are used [7]. Procedural skills is needed to support other mathematical skills, namely conceptual understanding [8]. Conceptual understanding and procedural skills are two different things but both support each other. Conceptual understanding leads todepth knowledge, while procedural knowledge leads to superficial knowledge [9]. A good conceptual understanding must be accompanied by good mastery of procedures. If students only master the concept without mastering the problem-solving procedure, students will have difficulty in relating a mathematical problem to the mathematical concept.

There are connections between procedural skills and working memory. Working memory used to obtain new information and integrate that information with information stored in long-term memory [10]. Rehearsal is needed to practice the procedural skills. Mastering procedural skills aims to enabling students to carry out procedures that involve memory, principles, and formula of mathematics to solve problems [11]. There are two things that measured in procedural skills; first, students are able to solve problems using more than one method, and second students are able to choose the right procedures to solve problems based on the situation [12]. This indicates that the importance of students mastering procedural skills to deal with unfamiliar problems and to get a better understanding of mathematical concepts.

\subsection{Difference Problem Solving Strategies between Experts and Novices}

There are different problem solving strategies used by experts and novices. Novices are students with less prior knowledge so they tend to solve problems using meansends analysis. And experts are students with high prior knowledge usually solve problems using forward strategy. Means-ends analysis strategy seeks to reduce the distance between problems and sub goals to find solutions [2]. Means-ends analysis allows students to obtain the solutions but it can cause working memory load so that learning is disrupted [13]. Meanwhile, experts are students with high prior knowledge so that they are able to categorize problems well and solve them effectively [2]. Experts are able to understand the problems and using forward strategies so solve them. Expert will focus into problem and looking for the information needed to reach the solution. It can be concluded that the fundamental difference between expert and novice is in the structure of knowledge [2]. Expert classifies and formulates solutions by implementing work-forward strategies and novice classify problems with low understanding.

\subsection{Worked Example Effects}

Cognitive load theory is an instructional theory that concerned into human cognitive system which is used to design effective learning strategies [3]. This theory emphasizes the importance of optimizing working memory and long term memory for processing information. This theory assumes meaningful learning occurs when strategy are able to reduce extraneous cognitive load and increase germane cognitive load. Extraneous cognitive load is the load produced by the presentation of learning material. A good presentation of learning material will provide low cognitive load even though the material considered difficult. Germane cognitive load is a space to process cognitive knowledge that is relevant to the material being studied. Therefore, worked example which are part of cognitive load theory are deliberately designed to reduce students' cognitive load while learning. This strategy is accompanied with explicit guidance of each step to facilitate students during learning.

The superiority of worked example has been widely proven by previous study that worked examples are able to help students by providing examples so that students more easily to understand the lessons [14]. Similar study also reveal that learning by worked examples individually will be more useful for students who do not have relevant knowledge in solving problems [17, 20]. Students can understand complex material with worked example than problem solving strategy $[16,19]$. Two things that become source of extraneous cognitive load which impact of worked example strategy are spit attention and redundancy effects. Split attention occurs when students are presented with two or more pieces of information which causes extraneous cognitive load [18]. This is because students have to divide their attention on several available sources. These sources include text, 
diagrams that are combined together, which causes the performance of working memory to be suppressed. Another case with split attention, redundancy effect occurs when students process information that is not needed [18]. In other words, multiple sources of information repeat the same information.

\section{METHOD}

This experiment used $2 \times 2$ factorial design by involving learning strategies (worked example vs problem solving) and levels of learner prior knowledge (expert vs novice). 118 junior high school students in Yogyakarta are asked to solved geometry problems and they devided into four groups: (1) worked example novice, (2) worked example expert, (3) problem solving novice, and (4) problem solving expert. This experiment went through three phases. First, introductory phase aims to introduce the lessons and as an activity to activate students' prior knowledge. Second, acquisition phase as an activity to devided students into four groups and they given different treatment. Third, test phase as students activity so solve geometry problems and writing down their procedures.

\section{RESULT AND DISCUSSION}

\subsection{Result}

The results showed there are strong connection between the effectiveness of learning strategies with levels of learner prior knowledge in terms of procedural skills. Based on the results of calculation using ANOVA showing the value of main effect $F=6,376$, $M S E=158,323, p=0,0139$, and $n_{p}^{2}=0,051$. Based on the value of eta square, it can be concluded that levels of students prior knowledge have an impact on the effectiveness of learning strategies. The following shows the test results of procedural skills from four groups after they received treatment.

Table 1. Data of procedural skills

\begin{tabular}{|l|l|c|c|}
\hline \multirow{2}{*}{$\begin{array}{c}\text { Learning } \\
\text { Strategy }\end{array}$} & \multicolumn{1}{|c|}{ Scale } & \multicolumn{2}{c|}{ Prior Knowledge } \\
\cline { 3 - 4 } & & Expert & Novice \\
\hline \multirow{3}{*}{$\begin{array}{l}\text { Problem } \\
\text { Solving }\end{array}$} & Total & 32 & 29 \\
\cline { 2 - 4 } & Average & 78,43 & 63,22 \\
\cline { 2 - 4 } & $\begin{array}{l}\text { Standard } \\
\text { deviation }\end{array}$ & 17,34 & 16,99 \\
\hline \multirow{3}{*}{$\begin{array}{l}\text { Worked } \\
\text { Example }\end{array}$} & Total & 31 & 30 \\
\cline { 2 - 4 } & Average & 70,97 & 70,23 \\
\cline { 2 - 4 } & $\begin{array}{l}\text { Standard } \\
\text { deviation }\end{array}$ & 17,50 & 17,97 \\
\hline
\end{tabular}

Based on the table, procedural skills of novice students increase by given worked example than problem solving strategy. Meanwhile, procedural skills of experts increase by given problem solving than worked example strategy. This indicates that prior knowledge of students also determines the effectiveness of learning strategies. Novice students with low prior knowledge need step by step guidance to led them into solutions. Besides, the results of the analysis showed that there is an interaction effect between strategic factors and prior knowledge factors. Experts' procedural skills increase if they gave problem solving strategy and novices' procedural skills increase if they given worked example strategy. The results of the analysis between the four treatment groups showed $\mathrm{F}(3,118)=3,862, M S E=158,323, p=0,011, n_{p}^{2}=$ 0,089 . Further analysis showed that problem solving strategy had strong effect for experts.

\subsection{Discussion}

Problem solving is a cognitive processing activity that occurs during learning. Problem solving refers to efforts to achieve goals [20]. Prior knowledge plays an important role in problem solving. Prior knowledge help students to understand the problems and help them to determine the strategies [1]. There are different problem solving strategies used by experts and novices. Novices tend to using means-ends analysis strategy and experts tend to using work-forward strategy [21]. Means-ends analysis is commonly known as backward strategy that starts from the goals to the sub goals. Therefore, novices need help such as examples that will help them find steps that will guide them to find solution. Otherwise, experts will focus on the problems and finds other information and then determine the strategies that will lead them to find solutions [21]. The following are the results of novices tasks given worked example and problem solving strategies.

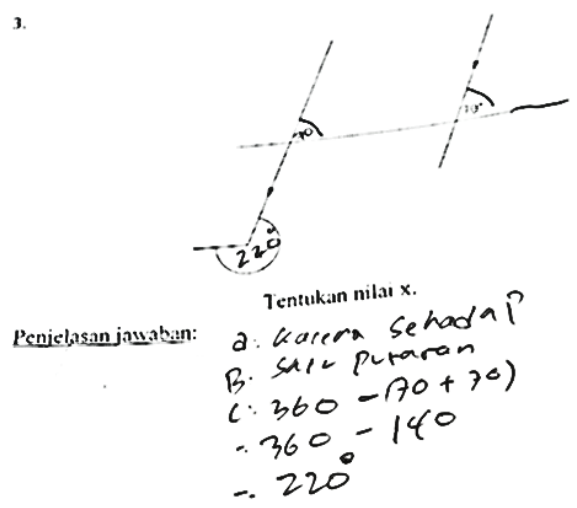

Figure 1 The result of novices with problem solving strategy

Figure 1 shows the work of novices who are given problem solving by applying means-ends analysis strategy. This strategy can interfere the acquisition of schema so that learning are not effective [24]. Novices are focused into the final goal by ignoring other 
information needed. In other words, novices focus on the final solution without seeing the problems and the information needed.

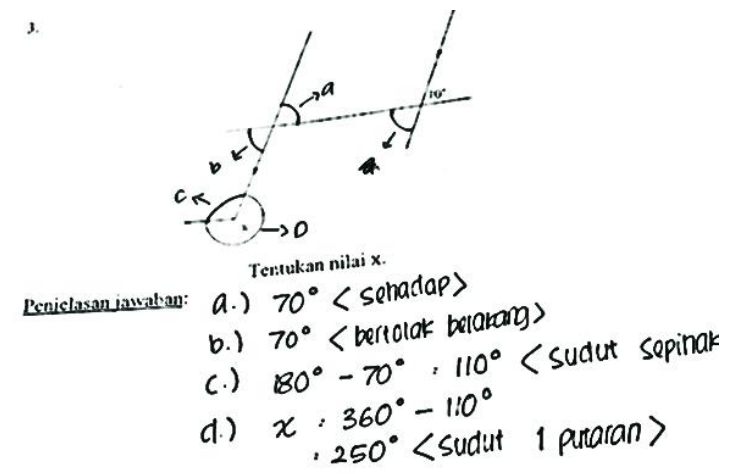

Figure 2 The result of novices with worked example strategy

Figure 2 shows the work of novice students who are given worked example strategy. The section shows students are able to solve problems with the right procedures and the right reasons. Students can systematically answer the questions starting from finding other angular information and applying some geometry theorems that have been learned.

This indicates that worked examples are effective for novices students because they are able to facilitate students in organizing their knowledge and borrowing information from examples. This finding is supported by previous research that worked examples are more effective if applied to novice students [19]. Other findings reveal that worked examples are more appropriate given to novices than problem solving [22]. When students do not have sufficient prior knowledge in solving problems, worked examples will be more effective [15]. Worked examples providing novices explicit guidance and relevant prior knowledge so that reducing working memory load and avoiding extraneous cognitive load.

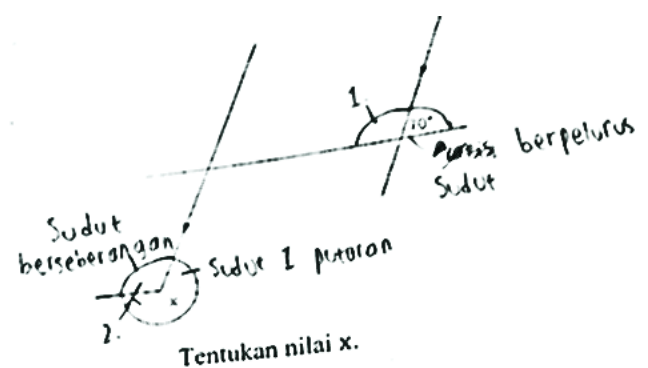

Penjelasan jawaban:

1. $=130^{\circ}-70^{\circ}=110^{\circ}$

2. $x=360^{\circ}-110^{\circ}=250^{\circ}$

Figure 3 The result of experts with problem solving strategy
Figure 3 shows one of the results of expert students who received problem solving strategy. Experts students only needs two steps in solving problems. The tendency of experts using work-forward strategy in solving problems leads them to focus on information needed to reach the solution [23].

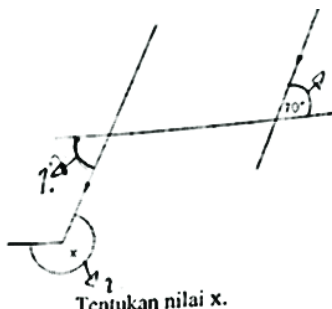

Penjeiasin jawaban:
1. $70^{\circ}$ (Sudut berseborangan)
7. $180^{\circ} \cdot 70^{\circ}, 110^{\circ}$ (Suctot berpeluros)

Figure 4 The result of experts with worked example strategy

Figure 4 shows the results of expert students who received worked example. Students are able to do several stages of solving problems correctly with the right reasons, but students do not find the final solution. The examples in worked example led to extraneous cognitive load and redundancy effect on experts. Redundancy effect occurs when students are presented with multiple information so that students must integrated that multiple source [18]. In other words, redundancy effects occurs when students are confronted with different sources of information simultaneously [2]. Repeating the same information will cause extraneous cognitive load. This also causes the integration of two sources of information that come from prior knowledge and worked examples. The crossing source of information between the two components makes working memory load on experts which can interfere learning [14]. Multiple sources of information repeat the same information. Information processing that is not needed by students will suppress extraneous cognitive load. This is susceptible happen to expert students who already have high prior knowledge.

Besides, these findings are confirmed by previous research which revealed that the limited of working memory of expert students by giving worked example would damage the scheme automation that students' problem solving activities are disrupted [24]. This is supported by Paas's statement that the effectiveness of learning strategies is related to the limitations of working memory [18]. Sweller reveal if a strategy had high effect on novice students but the strategy can lose its effectiveness if applied to expert students, this was known as the expertise reversal effect [14]. 


\section{CONCLUSION}

The findings showed worked example significantly enhance the procedural skills of students with less prior knowledge. In contrast, problem solving strategy significantly enhance the procedural skills of students with high prior knowledge. Besides, worked example led to extraneous cognitive load and redundancy effect for experts. Redundancy occurs when student are presented several information simultaneously. The integration of two sources of information that come from students prior knowledge and the examples. The crossing source of information between the two components makes working memory load so the problem solving activities of expert are interrupted. It means, problem solving strategy is more appropriates to enhance procedural skills of experts. The superiority of worked example in novice does not occur in expert. This is known as the expertise reversal effect, where the learning strategy highly effective for novice but the strategy have negative impact for expert.

\section{REFERENCES}

[1] Liljedahl P, Santos-Trigo M, Malaspina U, Bruder R. Problem solving in mathematics education. Problem Solving in Mathematics Education: Springer; 2016. p. 1-39.

[2] Retnowati E. Psychology of mathematics learning: Constructing knowledge. Yogyakarta: UNY. 2014.

[3] Paas F, Van Gog T, Sweller J. Cognitive load theory: New conceptualizations, specifications, and integrated research perspectives. Educational Psychology Review. 2010;22(2):115-21.

[4] Sweller J. Cognitive load theory. Psychology of learning and motivation. 55: Elsevier; 2011. p. 3776.

[5] Renkl A, Atkinson RK, Maier UH, Staley R. From example study to problem solving: Smooth transitions help learning. The Journal of Experimental Education. 2002;70(4):293-315.

[6] Rittle-Johnson B, Schneider M. Developing conceptual and procedural knowledge of mathematics. Oxford handbook of numerical cognition. 2015:1118-34.

[7] Long C. Maths concepts in teaching: Procedural and conceptual knowledge. Pythagoras. 2005;2005(62):59-65.

[8] Kilpatrick D, Linville M, Stout DE. Procedural justice and the development and use of peer evaluations in business and accounting classes. Journal of Accounting Education. 2001;19(4):22546.
[9] Star JR. Reconceptualizing procedural knowledge. Journal for research in mathematics education. 2005:404-11.

[10] Carlson RA, Sullivan MA, Schneider W. Practice and working memory effects in building procedural skill. Journal of Experimental Psychology: Learning, Memory, and Cognition. 1989;15(3):517.

[11] Zuya HE. Prospective Teachers' Conceptual and Procedural Knowledge in Mathematics: The Case of Algebra. American Journal of Educational Research. 2017;5(3):310-5.

[12] Schneider M, Rittle-Johnson B, Star JR. Relations among conceptual knowledge, procedural knowledge, and procedural flexibility in two samples differing in prior knowledge. Developmental psychology. 2011;47(6):1525.

[13] Ayres P, Sweller J. Locus of difficulty in multistage mathematics problems. The American Journal of Psychology. 1990:167-93.

[14] Kalyuga S, Ayres PL, Chandler P, Sweller J. The expertise reversal effect. 2003.

[15] Retnowati E, Ayres P, Sweller J. Can collaborative learning improve the effectiveness of worked examples in learning mathematics? Journal of educational psychology. 2017;109(5):666.

[16] Retnowati E, Ayres P, Sweller J. Worked example effects in individual and group work settings. Educational Psychology. 2010;30(3):349-67.

[17] Retnowati E, editor Learning mathematics collaboratively or individually. The 2nd International Conference of STEM in Education, Beijing Normal University, China Retrieved from http://stem2012 bnu edu cn/data/short\% 20paper/stem2012_88 pdf; 2012.

[18] Yeung AS, Jin P, Sweller J. Cognitive load and learner expertise: Split-attention and redundancy effects in reading with explanatory notes Contemporary educational psychology. 1998;23(1):1-21.

[19] Retnowati E, editor Worked examples in mathematics. 2nd International STEM in Education Conference; 2012.

[20] Schunk DH. Learning theories an educational perspective sixth edition: Pearson; 2012.

[21] Sweller J. Cognitive load during problem solving: Effects on learning. Cognitive science. 1988;12(2):257-85

[22] Van Gog T, Kester L, Paas F. Effects of worked examples, example-problem, and problem-example pairs on novices' learning. Contemporary Educational Psychology. 2011;36(3):212-8. 
[23] Kalyuga S, Chandler P, Sweller J. Levels of expertise and instructional design. Human factors. 1998;40(1):1-17.

[24] Renkl A, Atkinson RK. Structuring the transition from example study to problem solving in cognitive skill acquisition: A cognitive load perspective. Educational psychologist. 2003;38(1):15-22. 